\title{
Analisis Angka Partisipasi Kasar Pendidikan Anak Usia Dini (PAUD) di Seluruh Indonesia
}

\author{
Nani Rohmani ${ }^{凶}$ \\ Widyaiswara Ahli Madya Balai Diklat Keagaman Bandung Jawa Barat \\ DOI: $\underline{10.31004 / \text { obsesi.v5i1.262 }}$
}

\begin{abstract}
Abstrak
Pendidikan Anak Usia Dini (PAUD) adalah suatu upaya pembinaan yang ditujukan kepada anak sejak lahir sampai usia enam tahun. Perbandingan Pendidikan usia dini di Indonesia ternyata 55,4\% masih terbatas di perkotaan dan $44,6 \%$ di pedesaan karena masih tergantung pada partisipasi dan kemudahan orang tua untuk mencapai sekolah anak-anaknya. Sementara di pedesaan pendidikan usia dini ini kurang partisipasinya dari masyarakat dikarenakan pengetahuan akan pentingnya pendidikan usia dini sangat minim informasi dan sosialisasi tergantung pada pemangku kebijakan setiap provinsi di Indonesia. Penelitian ini bertujuan untuk mengetahui sebaran anak yang mengikuti PAUD dengan pengolahan data Angka Partisipasi Kasar (APK) dari Badan Pusat Statistik (BPS) dengan menghitung rata-rata dan rasio kemudian dianalisis dengan menggunakan statistik deskriptif. Hasil kajian ini menunjukkan bahwa sebaran di setiap provinsi di Indonesia tidak merata. Provinsi yang melampaui rata-rata nasional adalah Provinsi DI Yogyakarta dan terendah adalah Papua. Sedangkan rasio kenaikan dan penurunan APK anak yang mengikuti PAUD adalah $90 \%$ dari seluruh di Indonesia, hanya dua provinsi yaitu Kepulauan Riau dan DKI Jakarta yang mengalami penurunan rasio.
\end{abstract}

Kata Kunci: angka partisipasi kasar; pendidikan anak usia dini; sebaran.

\begin{abstract}
Early Childhood Education (PAUD) is an effort aimed at coaching children started from the birth till age of six. Comparison of early childhood education in Indonesia turned out to $55.4 \%$ which means quite limited in urban areas. On the other hand, the education in rural areas is $44.6 \%$ since still depending upon the participation and ease of parents to reach their children's schools. Early education in rural areas is lacking participation from the community, as the knowledge of early education is rather minimal and information of dissemination strongly relies on policy makers in each province. This study aims to determine the distribution of children attended PAUD by processing the Gross Enrollment Rate (GER) data from the Central Statistics Agency (BPS). It calculated the average and the ratio, then analyzed using descriptive statistics. The results of this study indicate that the distribution in each province in Indonesia is uneven. Province that exceeds the national average is the Province of DI Yogyakarta and the lowest is Papua. While the ratio of increase and decrease in APK for children attended PAUD is $90 \%$ of all Indonesia, excluding the Riau Islands and DKI Jakarta that decreased.
\end{abstract}

Keywords: rough participation rates; early childhood education; distribution.

Copyright (c) 2020 Nani Rohmani

$\square$ Corresponding author:

Email Address : nrohmani@gmail.com (Bandung, Jawa Barat)

Received 9 September 2019, Accepted 9 January 2020, Published 1 August 2020 


\section{PENDAHULUAN}

Setiap orang tua mendambakan anak-anaknya tumbuh dan berkembang sehat jasmani dan rohani, sehat secara fisik dan psikis, sehat akal dan jiwanya. Suryana (2007) dalam jurnalnya berpendapat bahwa setiap anak dilahirkan dengan potensi yang merupakan kemampuan (inherent component of ability) yang berbeda-beda dan terwujud karena interaksi yang dinamis antara keunikan individu anak dan adanya pengaruh lingkungan. Berbagai kemampuan yang teraktualisasikan beranjak dari berfungsinya otak kita. Berfungsinya otak, adalah hasil interaksi dari cetakan biru (blue print) genetis dan pengaruh lingkungan. Pada waktu manusia lahir, kelengkapan organisasi otak memuat sekitar 100-200 miliar neuron atau sel syaraf yang siap melakukan sambungan antarsel (Suryana, 2007).

Menurut Wulandari, Ichsan, \& Romadhon (2017) masa balita juga sebagai periode emas bagi orangtua untuk mengembangkan potensi anak secara optimal. Pada masa balita hampir seluruh sel-sel otak berkembang pesat. Tidak ada orang yang paling berarti dalam kehidupan seorang balita selain orangtuanya yang dapat memenuhi segala pertumbuhan dan perkembangannya. Kemampuan orangtua dalam memenuhi kebutuhan akan asuh, asih, dan asah akan mempengaruhi mutu kepribadian anak di kemudian hari (Yasbiati et al., 2018).

Dalam jurnalnya (Hermoyo, 2014) mengatakan bahwa Pendidikan Anak usia Dini dalam pembelajarannya bertumpu pada komunikator dan komunikan dalam menyampaikan suatu pesan. Komunikasi untuk anak usia dini tentu berbeda dengan orang dewasa. Pada anak usia dini, komunikasi harus selalu didampingi oleh orang tua ataupun orang dewasa. Sumarni (2017), menyatakan Pendidikan Anak Usia Dini (PAUD) tentunya berbeda dengan pendidikan lainnya, pendidikan anak usia dini memerlukan pendekatan yang unik, sabar dan kreatif, disesuaikan dengan masa perkembangannya yang unik pula. Dibutuhkan kesabaran dan kesungguhan dalam mendidik anak PAUD (Kartikowati, 2019).

Menurut Undang-undang tahun 2003 tentang sistem pendidikan nasional, menyatakan bahwa PAUD adalah suatu upaya pembinaan yang ditujukan kepada anak sejak lahir sampai usia enam tahun yang dilakukan melalui pemberian rangsangan pendidikan untuk membantu pertumbuhan dan perkembangan jasmani dan rohani anak agar anak memiliki kesiapan dalam mengikuti pendidikan lebih lanjut (Nasional, 2003)

Dalam jurnalnya, (Widiyawati Purnamasari, 2013) berpendapat bahwa perkembangan pendidikan PAUD tidak hanya mengutamakan pembangunan secara fisik namun juga mampu memberikan pelayanan optimal yang sesuai dengan Undang-undang dan peraturan yang berlaku. PAUD berfungsi membina, menumbuhkan dan mengembangkan seluruh potensi anak usia dini secara optimal sehingga terbentuk perilaku dan kemampuan dasar sesuai dengan tahap perkembangannya.

Menurut Nurmadiah (2016) dalam jurnalnya, semenjak disahkannya Undang-undang Pendidikan Nasional No. 20 tahun 2003 di Indonesia yang di dalamnya menyinggung masalah PAUD, diikuti dengan pembentukan Direktorat PAUD, maka perkembangan PAUD terasa semakin mantap, kesadaran masyarakat juga semakin nyata. Sedangkan Musnar (2016) menjelaskan di negara-negara maju penyelenggaraan PAUD telah berlangsung lama. Hal itu menjadi bagian dari bentuk pendidikan berbasis masyarakat. Sedangkan PAUD digalakkan di Indonesia baru muncul beberapa tahun terakhir. Dalam sebuah keluarga anak merupakan harapan dimasa depan dan orang tua memiliki peran penting dalam memberikan dukungan kepada anaknya untuk mencapai cita-cita di masa depan. Nurlaili (2018) menyatakan PAUD adalah usaha yang dilakukan oleh orang dewasa kepada anak usia 0-8 tahun dengan tujuan untuk mengembangkan potensi yang ada dalam diri anak sesuai dengan pertumbuhan dan perkembangan fisik dan rohaninya.

Ada tiga faktor yang berpengaruh kuat dalam membantu anak usia dini tumbuh kembang dengan baik, yaitu sekolah, lingkungan (masyarakat), dan keluarga. Keluarga merupakan pembentuk pribadi anak yang pertama karena waktu yang dihabiskan anak paling banyak di rumah, Pertumbuhan dan perkembangan anak berbeda-beda sesuai dengan bawaan masing-masing (Permono, 2013). Pendidikan Anak Usia Dini yang begitu cepat, 
tidaklah semudah mentransformasikan pemahaman yang merata kepada masyarakat luas tentang perlunya memberikan suatu bentuk pembelajaran secara terencana dan berjenjang kepada anak usia prasekolah (Rosdiana, 2006).

Hasil penelitian (Nengsi, 2019) berdasarkan hasil penelitian, sekitar 50\% kapabilitas kecerdasan orang dewasa telah terjadi ketika anak berumur 4 tahun, $80 \%$ telah terjadi ketika berumur 8 tahun, dan mencapai titik kulminasi ketika anak berumur sekitar 18 tahun (Direktorat PAUD, 2004).

Sri Lestari (2015) menjelaskan memberikan pendidikan untuk anak memang seharusnya diberikan sejak manak dalam usia dini untuk membentuk pribadi anak agar lebih siap menghadapi jenjang pendidikan selanjutnya. Program Pendidikan Anak Usia Dini (PAUD) ini pada awalnya dibentuk karena tingkat kesadaran masyarakat akan pentingnya memberikan pendidikan anak sebelum jenjang sekolah dasar masih cukup rendah. Pendidikan Anak Usia Dini (PAUD) ini memberikan pondasi yang kuat bagi anak agar di kemudian hari anak bisa menjadi sosok manusia berkualitas yang nantinya tampil sebagai generasi penerus bangsa yang siap berkompetisi di era globalisasi.

Anas, Riana, \& Apsari (2015) mengatakan pendidikan di kota memang sangat berbeda dibandingkan di desa, dimana kota adalah banyaknya informasi yang ada, dan juga adanya internet yang mendunia saat ini. sedangkan di desa tidak seperti itu bahkan mungkin sebaliknya. Fenomena pendidikan masyarakat perkotaan salah satunya yaitu, masyarakat kelas atas menyekolahkan anaknya di sekolah - sekolah mewah di saat masyarakat golongan ekonomi lemah harus bersusah payah bahkan untuk sekedar menyekolahkan anak mereka di sekolah biasa . Ketidakmampuan desa untuk berhadapan dengan pesatnya kemajuan kota salah satunya diakibatkan oleh kelemahan sistem pendidikan yang ada di desa itu sendiri. Seringkali pengembangan pendidikan yang diterapkan di sekolah-sekolah desa banyak yang tidak disesuaikan terlebih dahulu dengan kebutuhan yang ada di dalam masyarakat. Bahkan yang lebih memprihatinkan dalam penyusunan kurikulum terkadang disamakan dengan pengembangan kurikulum di sekolah-sekolah kota

Pendidikan usia dini di Indonesia ternyata masih terbatas di perkotaan karena masih tergantung pada partisipasi orang tua dalam pengelolaan PAUD dan aksesbilitas. Distribusi guru pada berbagai jenjang juga tidak merata (Mahbub et al., 2020). Misalnya di daerah perkotaan lebih banyak tempat penitipan anak dan kelompok bermain. Sebenarnya di pedesaan dan dari keluarga miskin jumlahnya lebih banyak dan membutuhkan pendidikan usia dini ini karena memberi keseimbangan kepada anak-anak yang berasal dari keluarga miskin ini karena miskin juga secara intelektual, sosial dan moral dari orang tua dan keluarga. Sehingga partisipasi pendidikan anak usia dini di Indonesia harus mulai dimaksimalkan sejalan dengan banyaknya penduduk di Indonesia terutama anak usia dini yang tergolong berusia 0-6 tahun.

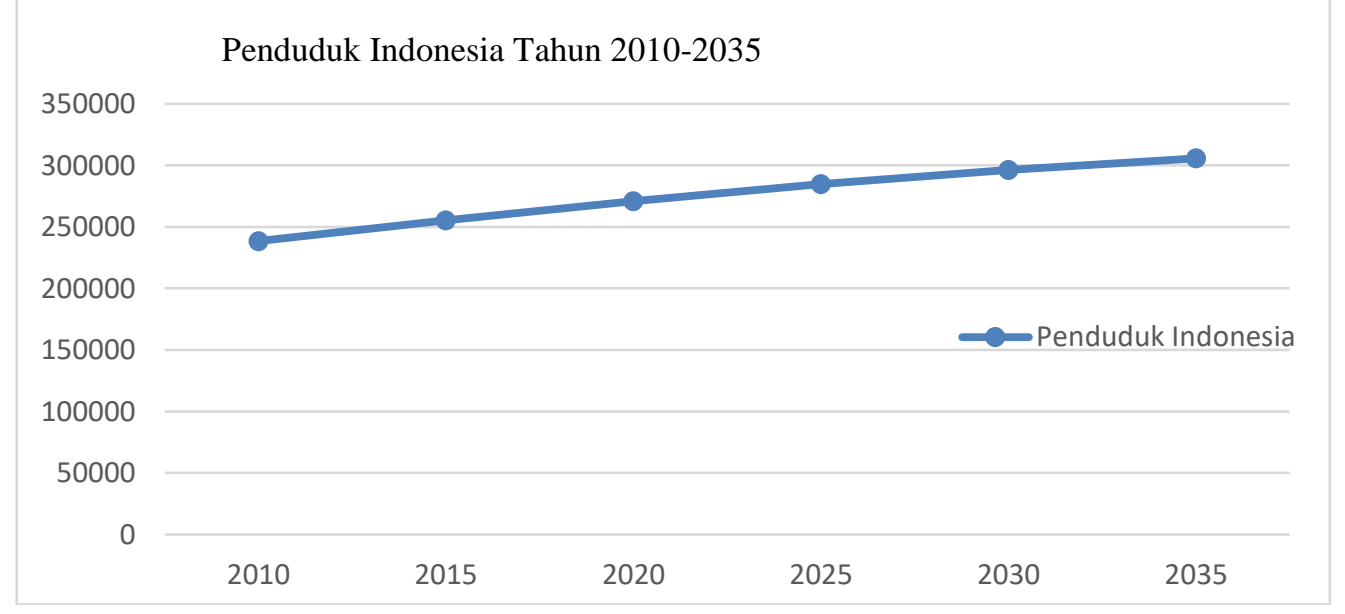

Gambar 1. Grafik Penduduk IndonesiaTahun 2010-2035(Sumber : Data BPS ) 
Penulis mengangkat topik ini melihat data BPS per 22 Juli 2019 tentang Angka Partisipasi Kasar anak yang mengikuti Pendidikan Usia Dini (PAUD) di seluruh Indonesia.

Hasil penelitian Istiqomah Anny, Sukidin, \& Pudjo (2018) menunjukan penduduk usia sekolah dilakukan dengan perbandingan antara siswa pada jenjang pendidikan tertentu dengan penduduk usia sekolah tertentu, tanpa melihat ketepatan usia dan dinyatakan dalam persentase. Dengan menganalisis Angka Partisipasi Kasar dari grafik di atas ternyata dari beberapa Provinsi di Indonesia menunjukkan asumsi yang bertolak belakang antara data dengan asumsi penulis, bahwa partisipasi pendidikan anak usia dini di perkotaan lebih banyak dibandingkan dengan di pedesaan. Penulis menemukan Pendidikan Usia Dini di beberapa pulau di Indonesia juga sebarannya tidak sama. Misalnya sebaran data BPS APK anak mengikuti PAUD di provinsi Jawa Barat ternyata lebih rendah dibanding dengan DI Yogyakarta dan Jawa Timur.

Dalam (Kartakusumah, 2018) Angka Partisipasi Kasar (APK) di pakai untuk mewakili indikator keberhasilan sektor pendidikan. Angka Partisipasi Kasar (APK) merupakan rasio jumlah siswa, berapapun usianya, yang bersekolah di tingkat pendidikan tertentu terhadap jumlah penduduk usia yang berkaitan dengan jenjang pendidikan tertentu. APK juga digunakan, untuk menunjukkan berapa besar tingkat partisipasi masyarakat secara umum disuatu tingkat pendidikan. Angka Partisipasi Kasar digunakan, untuk menunjukkan berapa besar tingkat partisipasi masyarakat secara umum disuatu tingkat pendidikan dan APK juga memiliki peran yang berarti di Indonesia, yaitu untuk mengetahui secara signifikan tingkat penduduk yang menyelesaikan pendidikan yang mana masih menghadapi banyak masalah dalam mengenyam pendidikan seperti putus sekolah atau tidak melanjutkan sekolah.

Pada dasarnya banyak faktor yang mempengaruhi nilai APK seperti pendapatan perkapita, Latar belakang pendidikan orang tua dan mata pencaharian, namun penelitian ini tidak membahas faktor-faktor tersebut hanya melakukan ulasan atau pembahasan umum tentang APK PAUD seluruh Indonesia.

Dari analisis data statistik BPS penulis bertujuan ingin mengetahui provinsi mana saja di Indonesia yang memiliki sebaran pendidikan usia dini yang mengalami peningkatan dan penurunan (fluktuatif) setiap tahunnya, provinsi mana saja yang memiliki peningkatan yang signifikan dengan perkembangan daerahnya. Dan Penulis bertujuan juga memberi analisis data BPS ini untuk informasi bagi pemangku kebijakan yang berkaitan dengan PAUD di Indonesia, Juga menjadi bahan bagi penulis sebagai bahan rujukan untuk penelitian selanjutnya

\section{METODOLOGI}

Penelitian ini menggunakan metodologi analisis statistik deskriptif. Pengolahan datanya dengan menggunakan excel dengan menghitung rata-rata (mean) dari data 4 tahun terakhir yaitu tahun 2015 sampai 2018 didapat grafik Analisis Partisipasi Kasar anak yang mengikuti pendidikan anak usia dini ("Rough Participation Rate of Early childhood education programs by Province") dari BPS per tanggal 22 Juli 2019.

Hasil analisis rata-rata dari data statistik ini dihitung untuk melihat sebaran pendidikan anak usia dini (PAUD) di provinsi seluruh Indonesia dan mengetahui provinsi mana saja yang mempunyai rata-rata Analisis Partisipasi Kasar Pendidikan Anak Usia Dini diatas rata-rata nasional ( $\mathrm{r}>$ nasional).

Rasio dihitung dengan membagi tiga periode 2015/2016, 2016/2017 dan 2017/2018 dari data Analisis Partisipasi Kasar Anak yang mengikuti Pendidikan Usia Dini untuk mengetahui mana saja provinsi yang mengalami peningkatan dan penurunan APK PAUD yang signifikan, mengalami peningkatan fluktuatif atau tidak mengalami peningkatan.

Angka Partisipasi Kasar (APK) Anak yang mengikuti Pendidikan Anak Usia Dini (PAUD) diperoleh dari : 


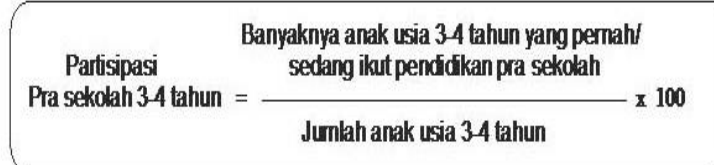

Catatan: Kelompok Umur: $3-4$ tahun, $5-6$ tahun, $3-6$ tahun

\section{Gambar Angka Partisipasi Kasar anak yang mengikuti PAUD} Sumber : BPS.go.id

Penulis mengambil rumus APK yang didapat dari BPS. Rumus di atas berlaku juga untuk penghitungan PAUD untuk usia 3-6 tahun.

\section{HASIL DAN PEMBAHASAN}

Dari hasil penelitian didapatkan, berdasarkan sebaran kecenderungan orang tua untuk menyekolahkan anak di PAUD pada grafik di atas maka penulis akan mendeskripsikan data tersebut. Pulau Jawa khususnya paling tinggi di Daerah Istimewa Yogyakarta diikuti dengan Jawa Timur, Jawa Tengah, DKI, Jawa Barat, Banten. Di Kepulauan Nusa Tenggara Barat (NTB) lebih tinggi daripada Bali dan Nusatenggara Timur (NTT) .

Sementara di pulau Sulawesi dari hasil pengolahan data penulis tertinggi di Gorontalo, Sulawesi tengah, Sulawesi Barat, Sulawesi Selatan, Sulawesi Tenggara dan Sulawesi Utara. Seperti ditunjukkan ditabel Partisipasi Kasar (APK) Anak yang mengikuti PAUD Menurut Provinsi di bawah. Ternyata hasil penelitian ini sesuai dengan hasil penelitian sebelumnya (Latief et al., 2019) bahwa di Sulawesi Tengah APK (Angka Partisipasi Kasar) PAUD terus naik signifikan. Pada tahun 2011, APK masih sebesar 42,82\%, 2012 naik menjadi 55,12\%, 2013 jadi 63,20\%, lalu 2014 naik lagi jadi 76,41\% dan 2015 telah mencapai 85,41\% sampai mencapai angka 88,12\%. Dari hasil pengolahan data disimpulkan bahwa Angka partisipasi PAUD di Sulawesi Tengah dari tahun 2011 - 2017 terus meningkat namun selama 2 tahun terakhir tergolong menurun yaitu ditahun 2018-2019. Sulawesi Tengah merupakan daerah dengan posisi tiga besar Nasional dalam peningkatan dan pengembangan PAUD di daerah sama-sama dengan Provinsi DI Yogyakarta dan Jawa Timur pada tahun 2016- 2017, Sulawesi Tengah mencapai angka partisipasi (APK) 90,5.

Di pulau Kalimantan tertinggi di Kalimantan Selatan, Kalimantan tengah, Kalimantan Utara, Kalimantan Timur dan Kalimantan Barat. Di pulau Sumatera tertinggi di Lampung, Bangka belitung, Jambi, Aceh, Sumatera utara, Sumatera Barat, Kepulauan Riau, Sumatera Selatan, Bengkulu dan Riau. Di Pulau Maluku utara lebih tinggi Maluku Barat. Di pulau Papua ternyata Papua barat lebih tinggi Papua dari tahun 2014 sampai dengan 2018.

Dibawah ini grafik 1 Angka Partisipasi Kasar (APK) Anak yang mengikuti PAUD Menurut Provinsi ("Rough Participation Rate of Early childhood education programs by Province") dari data BPS.

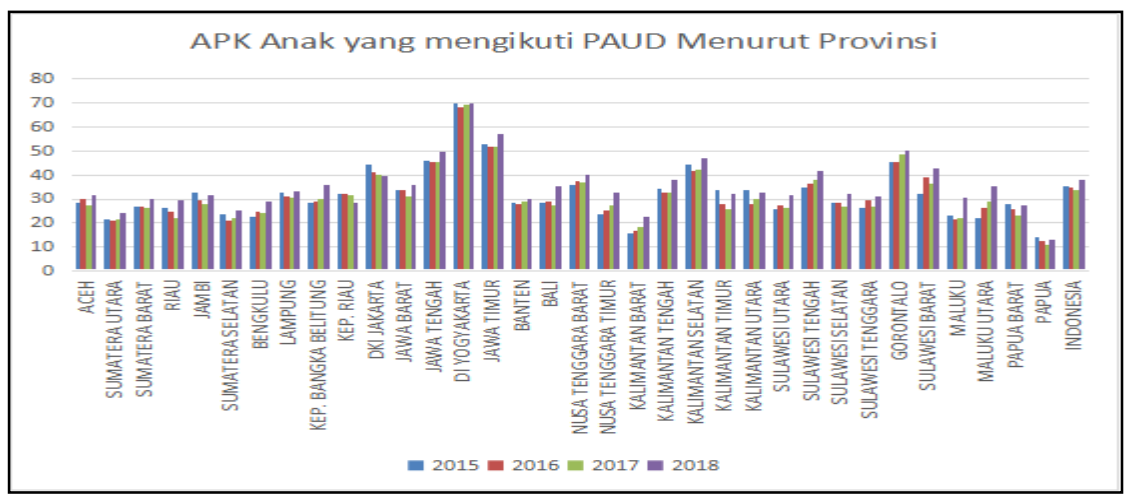

Grafik 1: Angka Partisipasi Kasar (APK) Anak yang mengikuti PAUD Menurut Provinsi ("Rough Participation Rate of Early childhood education programs by Province") Sumber: Data BPS 
Beberapa provinsi di Indonesia diambil rata-rata (mean) dari data Angka Partisipasi Kasar (APK) anak-anak mengikuti PAUD empat tahun terakhir di beberapa provinsi di Indonesia menunjukkan ada yang di atas rata-rata nasional ( $\mathrm{r}$ nasional $=35,39)$ tertinggi DI Yogyakarta ( $\mathrm{r}>$ nasional $=69,38)$, Jawa Timur $(\mathrm{r}>$ nasional $=53,385)$, Gorontalo $(r>$ nasional $=47,3375)$, Kalimantan Selatan $(r>$ nasional= 43,8375), DKI Jakarta $(r>$ nasional = 41,305), Nusa Tenggara Barat ( $r>$ nasional $=37,6525)$, dan Sulawesi Barat ( $r>$ nasional $=37,5225)$. Dari grafik di atas juga terlihat Provinsi yang tertinggi anak yang mengikuti Pendidikan Anak Usia Dini (PAUD) adalah DI Yogyakarta dan terendah adalah Papua.

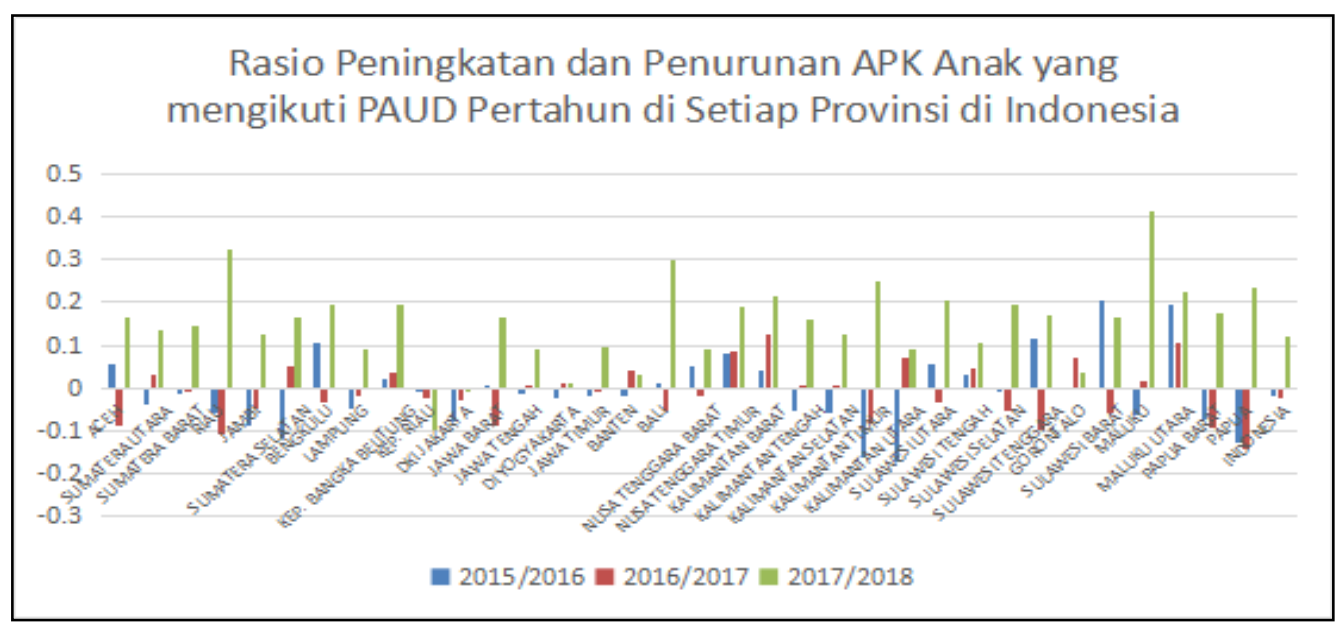

Grafik 2: Data hasil pengolahan APK anak yang mengikuti PAUD ("Rough Participation Rate of Early childhood education programs by Province")dihitung Rata-rata (Mean) dan Rasio kenaikan dan Penurunan pertahun setiap Provinsi di Indonesia. (Sumber data : BPS)

Berdasarkan grafik 2 di atas di dapat data Rasio kenaikan dan penurunan Angka Partisipasi Kasar (APK) anak yang mengikuti Pendidikan Anak Usia Dini (PAUD) pertahun . Misalnya warna biru rasio antara tahun 2015/2016, warna merah rasio antara tahun 2016/2017 dan warna hijau rasio antara tahun $2017 / 2018$. Sementara pada grafik di atas pada sumbu mendatar menunjukkan nama provinsi di seluruh Indonesia dari Aceh sampai Papua.

Setelah dicermati ternyata ada beberapa provinsi di Indonesia memiliki rasio kenaikan yang signifikan dan tidak mengalami penurunan selama masa periode empat tahun misalnya provinsi NTT, Kalimantan Barat, Kepulauan Bangka Belitung dan Sulawesi Tengah. Sementara itu provinsi Maluku Utara mengalami kenaikan tapi fluktuatif karena tahun 2015/2016 naik, tahun 2016/2017 turun tetapi tahun 2017/2018 mengalami kenaikan yang signifikan.

Ada beberapa provinsi yang mengalami rasio kenaikan dan penurunan APK anak yang mengikuti PAUD satu tahun yang sangat fluktuatif yaitu provinsi Aceh, Bali, NTB, Sulawesi Utara, Sulawesi Tenggara, dan Sulawesi Barat. Tetapi dari grafik di atas juga terlihat bahwa pada dasarnya 90\% provinsi di Indonesia rasio APK anak yang mengikuti PAUD meningkat secara signifikan terutama di tahun 2018. Sedangkan kondisi anak usia dini di Kabupaten Mamuju sampai akhir Desember 2015 tercatat telah terlayani sebanyak 6.451 anak dari jumlah anak usia dini 20.217 anak, atau baru mencapai 31,91\%. Selanjutnya, diketahui Angka Partisipasi Kasar (APK)-nya 30,91\% (Hajati, 2018)

Seperti penelitian sebelumnya ada di beberapa daerah mengalami penurunan dalam mengikuti PAUD menurut penelitian (Kartakusumah, 2018) berdasarkan hasil studi pendahuluan yang dilakukan pada bulan November 2013 di desa Tegal Tawanrejo Bareng, Klaten terdapat 80 anak berusia 4-5 tahun. Dari 80 anak terdapat 31 anak yang mengikuti pendidikan anak usia dini. Dari hasil pendataannya masih banyak terdapat anak yang belum mengikuti pendidikan anak usia dini dan anak-anak tersebut memiliki keterlambatan dalam perkembangannya dibandingkan anak-anak yang mengikuti pendidikan anak usia dini, yaitu 
didapatkan hasil bahwa anak yang mengikuti pendidikan usia dini dari 16 anak yang sesuai perkembangan hanya sebanyak 14 anak $(43,8 \%)$. Senada dengan hasil penelitian ini, (Rahmawati, 2015) mendapati masih banyak terdapat anak yang belum mengikuti pendidikan anak usia dini dan anak-anak tersebut memiliki keterlambatan dalam perkembangannya dibandingkan anak-anak yang mengikuti pendidikan anak usia dini.

Dari hasil penelitian penulis APK juga sangat ditentukan oleh 3 faktor, yaitu; (1) faktor keberadaan sekolah, antara perkotaan dan pedesaan, (2) faktor keberadaan orang tua, dan (3) faktor kebijakan pemerintah/Dinas Pendidikan terhadap implementasi.

Dari penelitian sebelumnya (Rohman \& Karimah, 2010) Secara umum, hasil penelitian ini difokuskan pada faktor-faktor yang mempengaruhi rendahnya partisipasi anak usia 4-6 tahun terhadap PAUD di kota Medan jika dilihat dari: (1) faktor keberadaan sekolah, (2) faktor kebaradaan orang tua, dan (3) faktor kebijakan pemerintah/Dinas Pendidikan. Dari ketiga faktor tadi peneliti menyimpulkan bahwa jika dilihat dari aspek keberadaan sekolah yang menyebabkan rendahnya partisipasi anak usia 4-6 tahun terhadap PAUdiantaranya lokasi sekolah, mutu sekolah, program sekolah, kompetensi guru, kompetensi kepala sekolah, ketersediaan sarana dan prasarana, serta promosi yang dilakukan sekolah; sedangkan dari aspek keberadaan orang tua, yang menjadi faktor yang mempengaruhi rendahnya partisipasi usia 4-6 tahun terhadap PAUD yaitu: faktor ekonomi, faktor persepsi orang tua, faktor lokasi sekolah, dan minat orang tua memasukkan anaknya ke PAUD; dan (3) dari aspek kebijakan pemerintah, perizinan tidak menjadi kendala dalam pengelolaan PAUD

Dari grafik di atas penulis menemukan di provinsi Kepulauan Riau dan DKI Jakarta tidak ada rasio kenaikan APK anak yang mengikuti PAUD hal ini mendorong penulis untuk melakukan penelitian lanjutan.

\section{SIMPULAN}

Dari hasil dan pembahasan penelitian diatas penulis mendapat kesimpulan bahwa Sebaran berdasarkan analisis rasio kenaikan dan penurunan Angka Partisipasi Kasar anak (APK) yang mengikuti Pendidikan Anak Usia Dini (PAUD) adalah 90\% seluruh Provinsi di Indonesia mengalami kenaikan signifikan, Ada beberapa provinsi yang mengalami rasio kenaikan dan penurunan APK anak yang mengikuti PAUD, yang sangat fluktuatif yaitu provinsi Aceh, Bali, NTB, Sulawesi Utara, Sulawesi Tenggara, dan Sulawesi Barat akan tetapi provinsi Kepulauan Riau dan DKI Jakarta mengalami penurunan. Sulawesi Tengah merupakan daerah dengan posisi tiga besar Nasional dalam peningkatan dan pengembangan PAUD di daerah sama-sama dengan Provinsi DI Yogyakarta dan Jawa Timur pada tahun 2016- 2017.

\section{UCAPAN TERIMA KASIH}

Terimakasih kepada Bapak Endan Suwandana, Ph.D, Ana Uluwiyah, S.ST.,M.T. sebagai pembimbing penelitian dan kepada Badan Pusat Statistik. Ucapan terimakasih juga kepada PUSDIKLAT Tenaga Administrasi Kemenag RI.

\section{DAFTAR PUSTAKA}

Anas, A. Y., Riana, A. W., \& Apsari, N. C. (2015). Desa Dan Kota Dalam Potret Pendidikan. Prosiding Penelitian Dan Pengabdian Kepada Masyarakat, 2(3), 418-422. https://doi.org/10.24198/jppm.v2i3.13592

Hajati, K. (2018). Pelaksanaan Pendidikan Holistik-Integratif dalam Pelayanan Kebutuhan Dasar Anak Usia Dini di Kabupaten Mamuju Sulawesi-Barat. Indonesian Journal of Educational Science (IJES), 1(1), 17-24. https:/ / doi.org/10.31605/ijes.v1i1.133

Hermoyo, P. R. (2014). Membentuk komunikasi yang efektif pada masa perkembangan. Jurnal Pedagogi, 1(1), 1-12.

Istiqomah Anny, Sukidin, \& Pudjo, S. (2018). Analisis Partisipasi Pendidikan pada Masyarakat 
Miskin Dusun Gumuk Limo Desa Nogosari Kecamatan Rambipuji Kabupaten Jember. Jurnal Pendidikan Ekonomi, 12, 227-235. https:/ / doi.org/10.19184/jpe.v12i2.8553

Kartakusumah, Y. (2018). Analisis Faktor yang Mempengaruhi Angka Partisipasi Kasar (APK) pada Pendidikan Anak Usia Dini Taman Kanak-Kanak. In Tugas Akhir,Skripsi,Tesis,Disertasi (S2) (p. 4). Universitas Pendidikan Indonesia.

Kartikowati, E. (2019). Implementasi Strategi Trilogi Mendidik Anak Usia Dini. Al Fitrah: Journal Of Early Childhood Islamic Education, 3(1), 68-78.

Latief, J. A., Awalunisah, S., Km, J. S., Palu, K., \& Tengah, S. (2019). Analisis Angka Partisipasi Kasar (APK) Pendidikan Anak Usia Dini di Sulawesi Tengah. Bomba: Jurnal Pembangunan Daerah, 1(2), 65-73.

Mahbub, M., Purnamawati, D., Maslamah, Sopakua, S., \& Fauziddin, M. (2020). Educational data mining with clustering technique on the distribution of civil servant teachers in Indonesia. Journal of Advanced Research in Dynamical and Control Systems, 12(6), 20972103. https://doi.org/10.5373/JARDCS/V12I6/S20201171

Musnar, I. (2016). Pembelajaran Terpadu pada Siswa Miskin Pendidikan Usia Dini di Pekanbaru Jurnal PAUD Tambusai. PGPAUD STK.

Nasional, D. P. (2003). Undang-Undang Nomor 20 Tahun 2003, Tentang Sistem Pendidikan Nasional. In Depdiknas. https:// doi.org/10.35362/rie280958

Nengsi, A. W. (2019). Analisis Problematika Anak Usia 3-5 Tahun Belum Mendapatkan Pendidikan di PAUD. Al Fitrah: Journal Of Early Childhood Islamic Education, 2(2), 300. https:/ / doi.org/10.29300/alfitrah.v2i2.2273

Nurlaili. (2018). Sumber Belajar dan Alat Permainan untuk Pendidikan Anak Usia Dini. 2(1), 242250.

Nurmadiah, N. (2016). Strategi Pembelajaran Anak Usia Dini. Al-Afkar: Jurnal Keislaman $\mathcal{E}$ Peradaban, 3(1), 1-28. https:// doi.org/10.28944/afkar.v3i1.101

Permono, H. (2013). Peran Orangtua dalam Optimalisasi Tumbuh Kembang Anak untuk Membangun Karakter Anak Usia Dini. Universitas Muhammadiyah Surakarta. http://publikasiilmiah.ums.ac.id/handle/11617/3994

Rahmawati, N. A. (2015). Hubungan Pendidikan Anak Usia Dini dengan Perkembangan Anak Usia 4-5 Tahun di Desa Tawanreja, Bareng, Klaten. Jurnal Involusi Kebidanan, 5(15), 7. http://jurnal.stikesmukla.ac.id/index.php/involusi/article/view/196

Rohman, A. A., \& Karimah, S. (2010). Faktor-faktor yang Mempengaruhi Rendahnya Motivasi Belajar. January, 95-108.

Sri Lestari, E. (2015). Analisis Program Pendidikan Anak Usia Dini (PAUD) di Kota Semarang. Skripsi, 1-17.

Sumarni, S. (2017). Pendidikan Anak Usia Dini dalam Perspektif Islam (Maemonah (ed.); Vol. 6, Issue 2). Fakultas Ilmu Tarbiyah dan Keguruan Universitas Islam Negeri (UIN) Sunan Kalijaga Yogyakarta, 2016 Penerbit Kurnia Kalam Semesta, Yogyakarta. https:/ / doi.org/10.29313/tjpi.v6i2.3195

Suryana, D. D. M. P. (2007). Dasar-Dasar Pendidikan TK. Hakikat Anak Usia Dini, 1, 1-65.

Widiyawati Purnamasari, W. (2013). Studi Perbandingan Pengembangan Layanan PAUD di Kecamatan Brebes Kabupaten Brebes dan di Kecamatan Bukalamba Kabupaten Brebes. Indonesian Journal of Early Childhood, 2(2), 50-57.

Wulandari, R., Ichsan, B., \& Romadhon, Y. A. (2017). Perbedaan Perkembangan Sosial Anak Usia 3-6 Tahun Dengan Pendidikan Usia Dini Dan Tanpa Pendidikan Usia Dini Di Kecamatan Peterongan Jombang. Biomedika, 8(1), 47-53. https:/ / doi.org/10.23917/ biomedika.v8i1.2900

Yasbiati, Y., Nugraha, D., Rahman, T., Nur, L., Nurzaman, I., \& Tajmiati, A. (2018). Pengembangan Program Bina Keluarga Balita Holistik Integratif (BKBHI) untuk Meningkatkan Tumbuh Kembang Anak Usia Dini di PAUD Kober Ceria. Prosiding Pengabmas, 1(1), 57-62. 